\title{
Frequency distributions in rainbow trout populations of absorbance values from an ELISA for Vibrio anguillarum antibodies
}

\author{
Margaret A. Thorburn, Eva K. Jansson \\ National Veterinary Institute, Box 7073, S-750 07 Uppsala, Sweden
}

\begin{abstract}
An enzyme-linked immunosorbent assay (ELISA) was used to measure Vibrio anguillarum serotype 1 antibody activity in sera collected from negative reference and from cohort-vaccinated and naturally exposed farmed rainbow trout Salmo gairdneri populations. Frequency histograms of each sample's absorbance values (OD) were prepared. Statistical distributions were fit to the data from the reference groups in order to determine seronegative, suspect and seropositive cut-off levels. The OD of reference populations followed either a normal or a log-normal distribution. The frequency histograms for the OD of vaccinated groups had a wide range and clustered around the median. From 57 to $88 \%$ of vaccinated trout were classified as seropositive. The $O D$ of naturally exposed groups were strongly skewed to the right, indicating elevated antibody production in at least part of the population (18 to $36 \%$ suspect or seropositive).
\end{abstract}

\section{INTRODUCTION}

The enzyme-linked immunosorbent assay (ELISA) for circulating specific antibody activity, because of its objective nature and rationalized design, may become a useful tool in seroepidemiologic studies of fish disease. However, high background levels of antibodies in commercially reared and wild fish could limit its applicability (Hamilton et al. 1987). Difficulties in distinguishing between low levels of specific reactivity and non-specific reactivity is a general, and critical, problem in the development of ELISA (Taylor et al. 1978, York et al. 1983). The probability of false positive results due to non-specific reactions can be reduced by using a relatively high positive-negative cut-off level; this will, however, increase the probability of false negative results.

Various methods have been used to determine cutoff levels for absorbance values (OD) to detect fish antibodies by ELISA. Some workers have used arbitrarily determined fixed levels (Bortz et al. 1984, CossariniDunier 1985). It is preferable to base cut-off levels on the frequency distribution of the $O D$ of negative sera (van Loon et al. 1981). Kodoma et al. (1985) and Thorburn (1986) set the minimum positive OD at the mean OD of samples collected from non-exposed populations plus 2 or 3 standard deviations of the mean. This method, however, is possibly invalid because it assumes the $O D$ in the negative population are normally distributed.

An ELISA to detect Vibrio anguillarum serotype 1 antibody in rainbow trout Salmo gairdneri has been developed in Sweden, and has been used to investigate the immunogenicity of vaccines (Thuvander et al. 1987) and to follow the immune response of vaccinated and non-vaccinated fish in field trials (Thorburn 1986). The objective of the present study was to determine the frequency distributions of OD provided by this ELISA system in selected populations of rainbow trout. The reason for investigating these distributions was 2 -fold. First, examination of the frequency distributions of $O D$ may be quite useful in seroepidemiologic studies for comparison of samples from 2 or more populations (Woodruff et al. 1978). Disparities in the forms and percentile markers of distributions may help elucidate subtle population differences which are not readily apparent from summary statistics. Second, determination of the frequency distribution of $O D$ in known specific-pathogen-free and known exposed or immunized populations is the best way to accurately estimate the true sensitivity and specificity of an ELISA. 


\section{MATERIALS AND METHODS}

Fish. The sampled rainbow trout populations originated from winter 1986 hatches on 3 commercial freshwater hatcheries $(F 1, F 2$, and $F 3$ ) in southern/central Sweden. Trout from each hatchery were transported to 1 of 3 brackish water (B1 and B3) or saltwater (S2) netpen farms. All trout designated for B1 and S2 were intra-peritoneally (IP) vaccinated prior to transport in the spring of 1987 . The negative reference (non-vaccinated) populations from F1 and F2 (F1REF and F2REF) were full-siblings of their vaccinated cohorts (B1VACC and F/S2VACC, respectively). Trout from F3 were transported to B3 in autumn 1986. Most of these fish were IP-vaccinated on site (B3) the following spring, 1987 (B3VACC); 1 pen of non-iP-vaccinated fish was retained (B3REF). The $\mathrm{F} 3$ and $\mathrm{B} 3$ populations had been dip-vaccinated at 3 to $5 \mathrm{~g}$ during summer 1986, 9 and 12 mo respectively prior to the first sampling occasion. The nature of the relationship between F3REF and the B3 population was not known. They had, however, been hatched and raised, until B3's transport, on the same small hatchery.

All vaccinations were done with commercially available formalin-killed bivalent vibriosis bacterins.

Blood samples. Blood samples were collected from the caudal vein, at the times and locations listed in Table 1 . After clotting overnight at $4^{\circ} \mathrm{C}$, samples were centrifuged at $300 \times g$ for $12 \mathrm{~min}$. The sera sere stored at $-20^{\circ} \mathrm{C}$ until tested with the ELISA.

ELISA. Sera from F1, B1, F2 and S2 were assayed in one run (Run 1) and sera from $F 3$ and $B 3$ in a second (Run 2).

Polystyrene microtitre plates (Linbro, Flow) were coated with Vibrio anguillarum serotype 1 (according to the system of Sørensen \& Larsen 1986) O-antigen. The plates were incubated overnight at room temperature, then washed 3 times in washing fluid Subsequently $100 \mu \mathrm{l}$ of fish serum (diluted 1: 100 in PBS with $0.5 \%$ Tween 20) was added to each of the wells. Duplicate wells were used for each serum sample. After incubation at $4{ }^{\circ} \mathrm{C}$ for $20 \mathrm{~h}$, the plates were washed 3 times and rabbit anti-trout immunoglobins (IgM) conjugated to horse radish peroxidase (diluted in PBS containing $0.5 \%$ Tween 20 and $1 \%$ horse serum) was added to each well. The plates were incubated at $4^{\circ} \mathrm{C}$ for 15 to $20 \mathrm{~h}$. After washing, trimethyibenzidine (TMB, Sigma) in acetate buffer with $\mathrm{H}_{2} \mathrm{O}_{2}$ was added to the microtitre wells. The reaction was stopped with $\mathrm{H}_{2} \mathrm{SO}_{4}$ and the optical density was read spectro-photometrically at $450 \mathrm{~nm}$. This method is described in detail by Thuvander et al. (1987)

Control sera. Control positive and negative sera were included in triplicate on every plate. These pooled sera originated from rainbow trout reared in flowing pathogen-free ground water aquaria; positive trout had been repeatedly injected with a formalinkilled vibriosis bacterin. In addition 2 high $O D$ (B3VACC) sera and 2 low OD (F1REF and F3REF) sera were included, in duplicate, on every plate.

Statistical analysis. The average $O D$ of the 7 negative wells $\left(\overline{\mathrm{OD}}_{\text {neg }}\right)$ on each plate was determined.

Table 1. Salmo gairdneri. Summary of sampled populations and sampling scheme for determination of frequency distributions of absorbance values from an ELISA for Vibrio anquillarum antibodies in rainbow trout.

\begin{tabular}{|c|c|c|c|c|c|c|c|}
\hline \multirow[t]{2}{*}{ Source $^{a}$} & \multirow[t]{2}{*}{ Group } & \multirow{2}{*}{$\begin{array}{c}\text { IP vaccination } \\
\text { date }\end{array}$} & \multicolumn{5}{|c|}{ Sampling procedure } \\
\hline & & & Site $^{a}$ & Date & $\begin{array}{l}\text { Water temp. } \\
\qquad\left({ }^{\circ} \mathrm{C}\right)\end{array}$ & $\begin{array}{l}\text { Fish size } \\
\qquad(g)\end{array}$ & $n$ \\
\hline \multirow[t]{2}{*}{$\mathrm{F} 1$} & F1REF & No & F1 & Jun 87 & 12 & 70 & 65 \\
\hline & B1VACC & May 87 & B1 & Jun 87 & 15 & NA & 42 \\
\hline \multirow[t]{2}{*}{ F2 } & F2REF & No & $\mathrm{F} 2$ & Apr 87 & 3 & 200 & 64 \\
\hline & $\begin{array}{l}\text { F2VACC } \\
\text { S2VACC }\end{array}$ & $\begin{array}{l}\text { Nov } 86 \\
\text { Nov } 86\end{array}$ & $\begin{array}{l}\mathrm{F} 2 \\
\mathrm{~S} 2\end{array}$ & $\begin{array}{l}\text { Apr } 87 \\
\text { Aug } 87\end{array}$ & $\begin{array}{r}3 \\
15\end{array}$ & $\begin{array}{l}200 \\
\text { NA }\end{array}$ & $\begin{array}{l}32 \\
31\end{array}$ \\
\hline \multirow[t]{3}{*}{ F3 } & F.3REF & $N o^{b}$ & F3 & May 87 & 7 & 35 & 75 \\
\hline & $\begin{array}{l}\text { B3REF1 } \\
\text { B3REF2 } \\
\text { B3REF3 }\end{array}$ & $\begin{array}{l}\mathrm{No}^{b} \\
\mathrm{No} \\
\mathrm{No}^{b}\end{array}$ & $\begin{array}{l}\text { B3 } \\
\text { B3 } \\
\text { B3 }\end{array}$ & $\begin{array}{l}\text { Jun } 87 \\
\text { Jul } 87 \\
\text { Sep } 87\end{array}$ & $\begin{array}{r}7 \\
17 \\
11\end{array}$ & $\begin{array}{r}65 \\
\text { NA } \\
\text { NA }\end{array}$ & $\begin{array}{l}32 \\
36 \\
33\end{array}$ \\
\hline & $\begin{array}{l}\text { B3VACC2 } \\
\text { B3VACC } 3\end{array}$ & $\begin{array}{l}\text { Jun } 87^{\mathrm{b}} \\
\text { Jun } 87^{\mathrm{b}}\end{array}$ & $\begin{array}{l}\text { B3 } \\
\text { B3 }\end{array}$ & $\begin{array}{l}\text { Jul } 87 \\
\text { Sep } 87\end{array}$ & $\begin{array}{l}17 \\
11\end{array}$ & $\begin{array}{l}\mathrm{NA} \\
\mathrm{NA}\end{array}$ & $\begin{array}{l}37 \\
10\end{array}$ \\
\hline \multicolumn{8}{|c|}{$\begin{array}{l}{ }^{a} \mathrm{~F} 1, \mathrm{~F} 2 \text { and } \mathrm{F} 3 \text { were commercial freshwater hatcheries located in southern/central Sweden. B1, S2 and B3 were commercial } \\
\text { brackish/salt water net-pen farms on the south (B1), west (S2) and east (B3) coast of Sweden }\end{array}$} \\
\hline
\end{tabular}


3 are based on the corrected $O D$, as described earlier. For instance, $\mathrm{OD}$ from the plate with the highest $\overline{\mathrm{OD}}_{\text {reg }}$ in. Run 1 were corrected by subtracting 0.06 (0.11 $0.05)$ prior to inclusion in any analysis or graphics.

\section{Reference populations}

Table 2 lists the summary statistics and cut-off levels for F1REF, F2REF, F3REF and B3REF1. The observed and fitted distributions of OD in F1REF, F2REF and B3REF1 are shown in Fig. 1.

The frequency distributions of F3REF and B3REF1 differed significantly. Since the nature of the relationship between F3REF and B3REF1 was unknown, we decided to use B3REF1 to determine the cut-off limits for classification of the subsequent samplings of B3REF and for B3VACC. The median OD of B3REF1 was significantly lower than that of F3REF, suggesting that no serological response to environmental levels of Vibrio anguillarum had occurred during the fish's first $7 \mathrm{mo}$ in brackish water. In the period between transport and the first sampling, B3 water temperatures had never exceeded $7^{\circ} \mathrm{C}$ and no sign of $V$ anguillarum infection had been noted.

Neither the median OD nor the distributions of F1REF and B3REF1 differed significantly from one another. The medians and distributions of both groups, however, differed significantly from F2REF.

\section{Vaccinated populations}

Fig. 2 presents the observed distributions of ODs from the IP-vaccinated groups. The OD in all groups showed a broad distribution. Some fish in each group had $O D$ below or in the region of 'suspect' classification, the majority had OD near their group's median $O D$, and some had extremely elevated values.

Table 3 lists the median OD and the sero-classification percentages of each vaccinated group. The estimated test sensitivities were 0.81 in B1VACC, 0.84 in F2/ S2VACC (determined by dividing the total number of seropositives by the total number sampled in both groups) and 0.60 for B3VACC2/3. The OD distributions of F2VACC and S2VACC did not differ significantly from one another.

\section{Exposed population}

The distributions of the ODs of B3REF2 and B3REF3 are shown in Fig. 3. The distributions were skewed to the right, indicating that a small proportion of fish had substantially higher ODs than did most of the fish.

Table 2 lists of the 95th percentiles for B3REF2 and
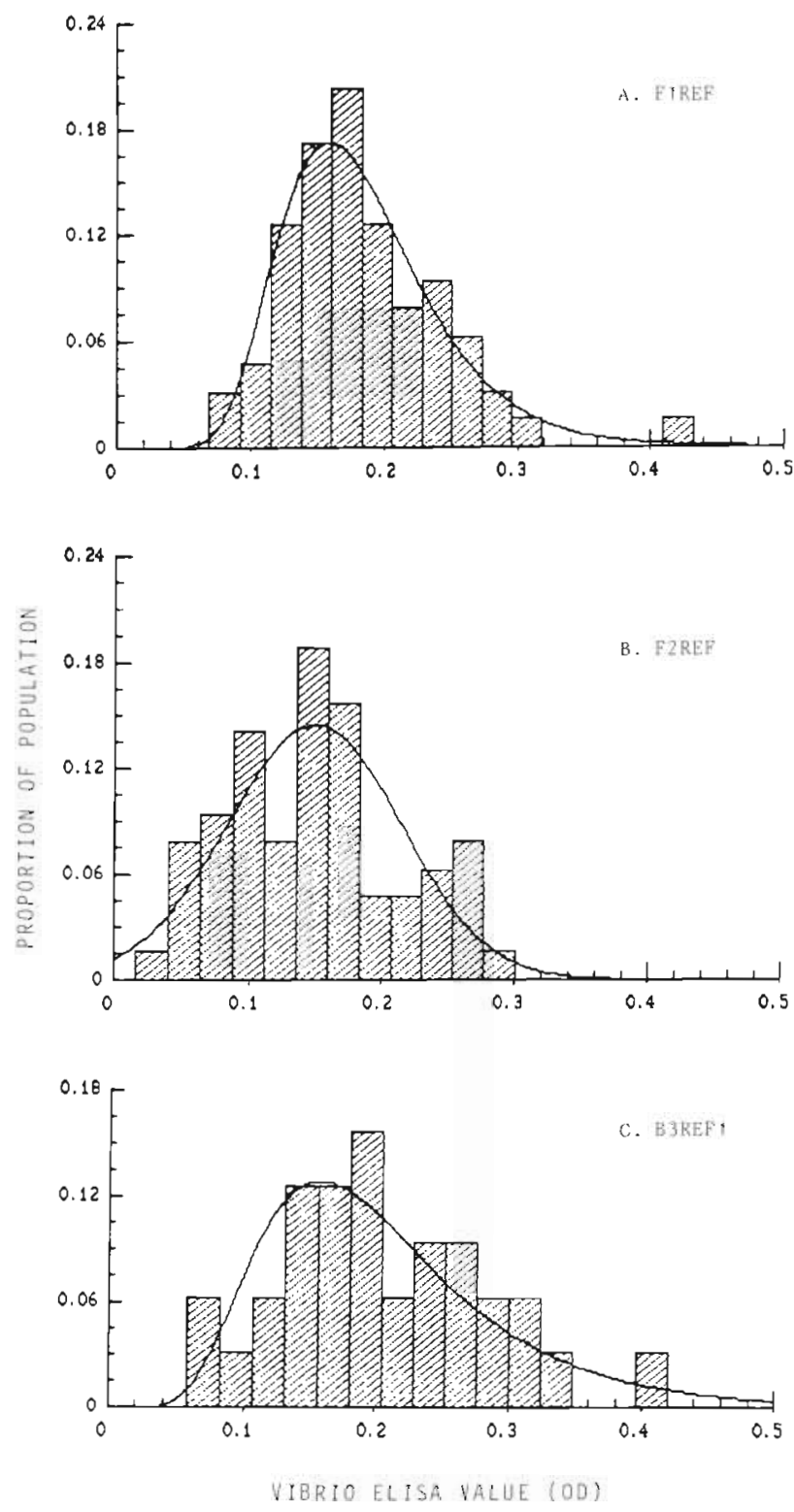

Fig. 1. Salmo gairdneri. Observed and fitted distributions of vibrio ELISA values among reference populations of rainbow trout. (A) Group F1REF. (B) Group F2REF. (C) Group B3REF1. Groups F1REF and F2REF had no previous exposure to the bacterium. Group B3REF1 was dip-vaccinated 1 yr prior to sampling, at an average weight of 3 to $5 \mathrm{~g}$

B3REF3 and Table 3 presents the median OD and seroclassification percentages. The median of B3REF2 was significantly higher than that of B3REF1 and B3REF3.

\section{DISCUSSION}

In order to fully exploit the potential of ELISA in fish disease research and control, meaningful methods of expressing the output data, OD, must be developed. A 

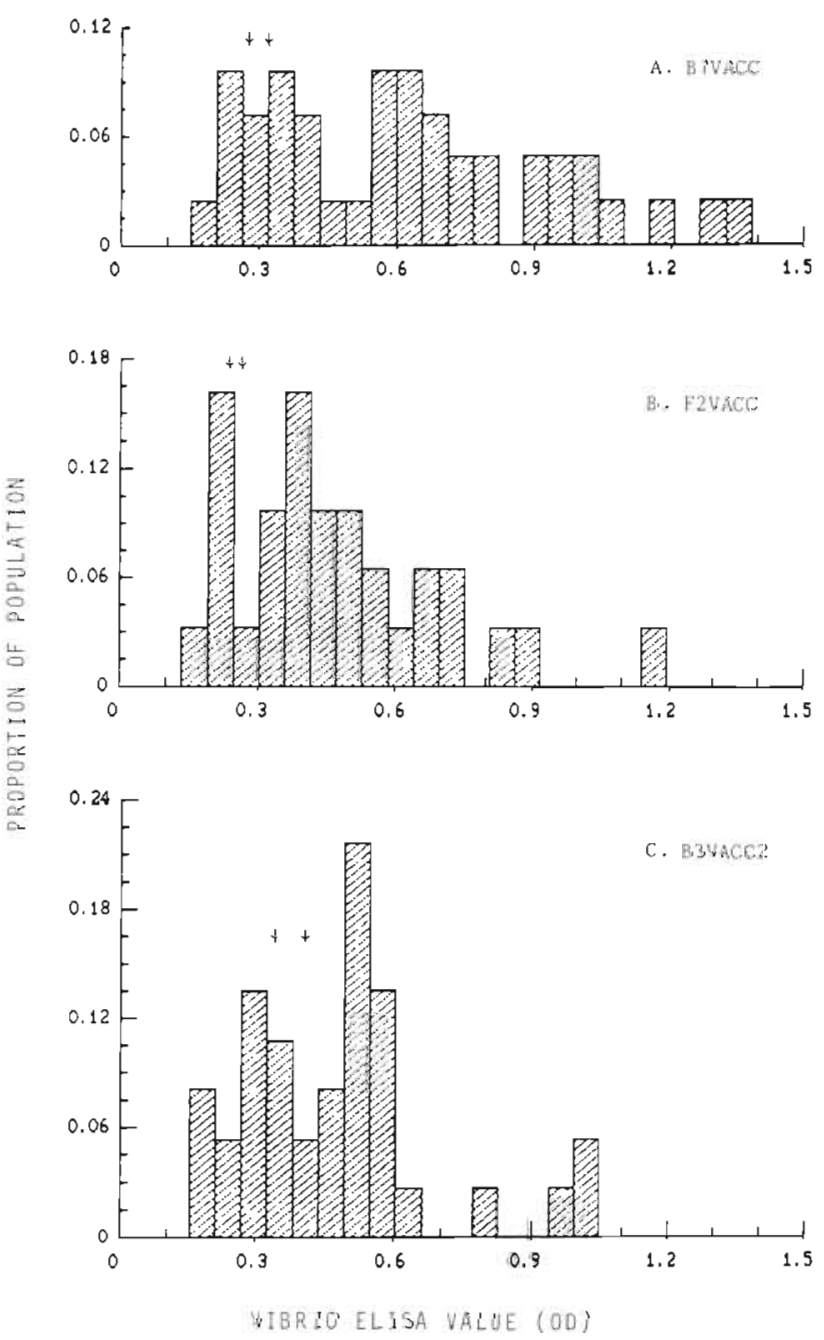

Fig. 2. Salmo gairdneri. Observed distributions of vibrio ELISA values among populations of rainbow trout following IP-vaccination. (A) Group B1VACC. (B) Group F2VACC. (C) Group B3VACC2. Group B3VACC2 was also dip-vaccinated, more than 1 yr prior to sampling. Arrows indicate $\mathrm{L}_{\mathrm{Cl}}$ and $\mathrm{U}_{\mathrm{CI}}$ as defined in Table 2, determined from the OD distributions of F1REF (A), F2REF (B) and B3REF1 (C)

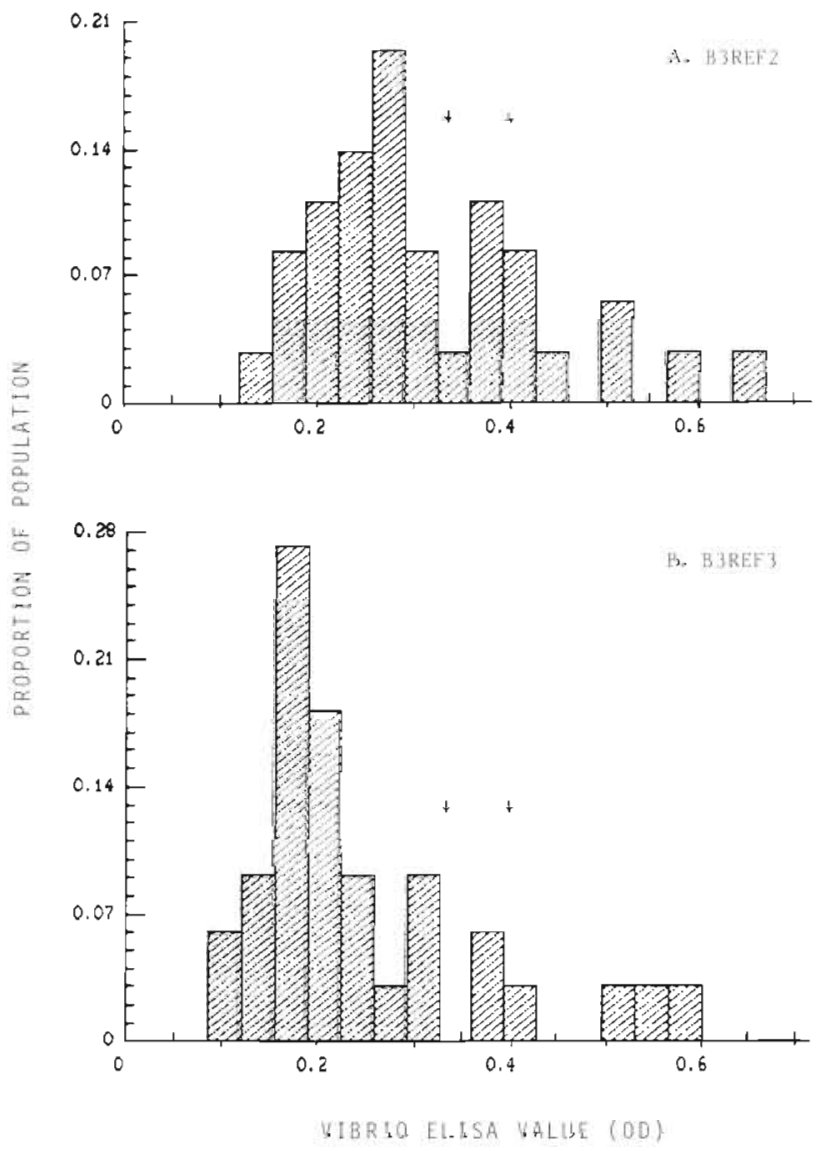

Fig. 3. Salmo gairdneri. Observed distributions of vibrio ELISA values among a population of naturally exposed rainbow trout. (A) Group B3REF2. (B) Group B3REF3. This population had been dip-vaccinated more than 1 yr prior to sampling. Vibriosis mortalities occurred in the population after sample B3REF2, but before sample B3REF3 was taken.

Arrows indicate $\mathrm{L}_{\mathrm{Cl}}$ and $\mathrm{U}_{\mathrm{Cl}}$, as defined in Table 2, determined from the OD distribution of B3REF1

Tabie 3. Salmo gairdneri. Median absorbance values (OD) and percentages of sampled rainbow trout classified as Vibrio anguillarum seronegative, suspect and seropositive in vaccinated and exposed populations

\begin{tabular}{lcccc|}
\hline Group $^{\text {a }}$ & Median OD & \% neg & \% suspect & pos \\
\hline B1VACC & 0.60 & 12 & 7 & 81 \\
F2VACC & 0.42 & 16 & 3 & 81 \\
S2VACC & 0.43 & 6 & 6 & 88 \\
B3VACC2 & 0.53 & 27 & 16 & 57 \\
B3VACC3 & 0.49 & 10 & 20 & 70 \\
B3REF2 & 0.28 & 64 & 17 & 19 \\
B3REF3 & 0.20 & 82 & 9 & 9
\end{tabular}

a Groups are described in Tabie 1

The following reference populations were used: F1REF for B1VACC, F2REF for F2VACC and S2VACC, B3REF1 for B3VACC2, B3VACC3, B3REF2 and B3REF3 
critical initial step in this process is to investigate the variation of $O D$ in negative populations and in diseased and immunized populations. Workers in human and veterinary medicine have found the distribution of ELISA values in non-diseased populations to follow a normal pattern (van Loon et al. 1981) or to have a positive skew (de Savigny et al. 1979, Gillis et al. 1984). Quantitative information on the distribution in diseased populations is less available.

Studies of the distribution of measured antibodies in fish populations are scarce. Robohm et al. (1979) examined the distribution of $\log _{10}$ values of agglutination titres to various bacterial antigens in flounder and weakfish. This information was then used to classify sampled populations of fish either having had no recent exposure to a specific antigen (Polsson distribution), or as having had a recent exposure (normal or 'mixed' distribution). Dunier (1983) estimated the variances of agglutination titres obtained in rainbow trout injected with dinitrophenol bound to the carrier, keyhole limpet haemocyanin, and found them to be considerably higher than variances found in positive mammalian populations. Although the continuous nature of ELISA data lends itself readily to distribution-fitting, comparable studies on the variation of ELISA values in fish populations have not been published.

The OD of the reference populations in this study followed either a normal or a log-normal distribution. Group F2REF had a normal distribution and a significantly lower median OD than the other reference groups. The blood samples from this group were collected at a lower water temperature and earlier in the year than were the other reference samples. These factors may have contributed to a lower background level of cross-reactive antibodies. Differences in the background readings of negative serological samples have also been attributed to husbandry (Taylor et al. 1978) and environmental (Grab \& Pull 1977) effects

Groups F1REF and B3REF followed log-normal distributions. Characteristics of the log-normal distribution include a concentration of individuals near the low end of the range and a moderate positive skew The right-hand tail incorporated, most likely, a small proportion of individuals with some non-specific reactivity. In the B3 reference group, it may, however, also have reflected fish with resicual specific antibody activity. F3REF and B3REF1 had been dip-vaccinated during summer 1986. We believed, when planning this study, that antibodies elicited by these vaccinations should have declined to background levels prior to our sampling in 1987. However, elevated vibrio titres have been detected by ELISA in aquaria-maintained rainbow trout for up to $46 \mathrm{wk}$ after dip-vaccination at $12 \mathrm{~g}$ (Thuvander et al. 1987). Although the duration of elevated titres decreases when fish are reared in the field, as opposed to the laboratory, and are vaccinated at smaller sizes (M. A. Thorburn unpubl.), some of the sampled F3 and B3 reference fish may have had residual specific antibody activity. The presence of specific reactivity was more probable in F3REF, which had a significantly higher median OD than B3REF1, and a different (normal) distribution. F3REF was vaccinated later and sampled earlier than B3REF1. Since there is variation among individual fish in the rate at which they lose specific antibody activity, OD frequency distributions will be time-dependent in vaccinated populations.

The frequency histograms of the IP-vaccinated groups revealed quite similar profiles. An initial peak was consistently observed near the cut-off region, indicating that a small proportion of fish did not respond to IP-vaccination with significantly elevated antibody production. This finding confirms the phenomenon of individual antibody non- (or poor-) responders in fish populations (M. Tatner pers. comm. 1987).

The statistical comparison of samples F2VACC and S2VACC showed no change in the OD distribution following the occurrence of vibriosis in S2VACC. While secondary exposure may have helped maintain antibody levels, it did not appear to cause an increase in the titres of individual fish, or to stimulate antibody production among the non-responder proportion of the population

At a given cut-off level, test sensitivity is a function of both the quality (accuracy and precision) of the ELISA and of the frequency distribution of the true $O D$ in the positive populations. Because of the occurrence of nonresponders, any test which requires the presence of circulating antibody for identification of positive fish cannot approach $100 \%$ sensitivity. The sensitivity of the ELISA in B1VACC and F2/S2VACC was, however, quite reasonable. It was not as good in the $B 3$ vaccinates. The relatively higher mean $O D$ and larger standard deviation in B3REF1 resulted in a higher positive cut-off level for the classification of B3VACC.

The OD of B3REF1 were significantly higher than those from the same population sampled $7 \mathrm{wk}$ earlier (B3REF1). Apparently, environmental levels of Vibrio anguillarum became, at some point, high enough to stimulate humoral immune responses in at least part of the B3REF population. That the first vibriosis mortal i.ties occurred ca 3 wk after sampling B3REF2 suggests that: (1) when initiated by low environmental pathogen concentrations, vibriosis may have a long incubation period, or (2) the mere presence of $V$. anguillarum, at levels which can elicit antibody production in some fish, is not sufficient cause for a disease outbreak. Thorburn (1986) has previously demonstrated the dosedependency of the incubation period for vibriosis. Rosenkvist-Jensen (1983) and Thorburn (1986) have 
observed vibrio antibody production in field-tested rainbow trout populations which remained diseasefree.

The occurrence of elevated ELISA values in the B3REF population was fairly transitory. By the final sampling (B3REF3), most OD were similar to those observed in the first sampling. However, relatively more fish were classified as suspect or seropositive in B3REF3 (18\%, as opposed to $3 \%$ in B3REF1). Also, B3REF3 had a much higher 95th percentile $(0.55)$ than did B3REF1 (0.37).

In conclusion, we suggest that no single method for interpretation of ELISA data will suffice for all aspects of fish disease work. Determination and comparison of median OD values may be adequate to assess humoral responses to immunization, but may not be sensitive enough to ascertain natural exposure in seroepidemiologic surveys. In the latter case, examination of the form and percentile markers of the OD frequency distributions in representative samples should provide helpful complementary information. Cut-off levels, which allow estimation of percent sero-positive, are valuable if they are based on the OD frequency distribution of comparable negative reference populations (Mainland 1971). Further research is necessary to determine which specific fish and environmental characteristics must be similar to achieve adequate comparability.

Acknowledgements. This research was supported by funds provided by the Swedish Council for Forestry and Agricultural Research (981-84; V 18:2).

\section{LITERATURE CITED}

Bortz, B. M., Kenny, G. E., Pauley, G. B., Garcia-Ortigoza, E., Anderson, D. P. (1984). The immune response in immunized and naturally infected rainbow trout (Salmo gairdneri) to Diplostomum spathaceum as detected by enzyme-linked immunosorbent assay (ELISA). Dev. comp. Immunol. 8: 813-822

Cossarini-Dunier, M. (1985). Indirect enzyme-linked immunosorbent assay (ELISA) to titrate rainbow trout serum antibodies against two pathogens: Yersinia ruckeri and Egtved virus. Aquaculture 49: 197-208

de Savigny, D., Voller, A., Woodruff, A. W (1979). Toxocariasis: serological diagnosis by enzyme immunoassay. J. clin. Pathol. 32: 284-288

Dunier, M. (1983). Cited in Michel, C., Tixier, G., Mevel, M. (1984). Evaluation of the protective activity and economic efficacy of vaccines for fish. In: de Kinkelin, P. (ed.) Symposium on fish vaccination, Paris, February 1984. Office International des Epizooities, p. 75-96

Elveback, L. R., Taylor, W. F. (1969). Statistical methods of estimating percentiles. Ann. N. Y. Acad. Sci. 161. 538-548

Gillis, J. M., Smith, R. D., Todd, K. S. (1984). Diagnostic criteria for an enzyme-linked immunosorbent assay for heartworm disease: standardization of the test system in naturally exposed dogs. Am. J. vet. Res. 45: 2289-2290

Grab, B., Pull, J. H. (1977). Statistical considerations in serological surveys of population with particular reference to malaria. J. trop. Med. Hyg. 77: 222-232

Hamilton, A. J., Fallon, M. J. M., Alexander, J., Canning, E. J. (1987). A modified enzyme linked immunosorbent assay (ELISA) for monitoring antibody production during experimental Aeromonas salmonicida infection in rainbow trout (Salmo gairdneri). Dev. comp. Immunol. 11: 253-258

Lilliefors, H. W (1967). On the Kolmogorov-Smirnov test for normality with mean and variance unknown. J. Am. Stat. Assoc. 62: 399-402

Kodoma, H., Honda, A., Moustafa, M., Mikami, T., Izawa, H (1985). Detection of antibody in rainbow trout against Aeromonas salmonicida by enzyme-linked immunosorbent assay. Fish Pathol. 20: 237-242

Mainland, D. (1971). Remarks on clinical 'norms' Clin. Chem. 17. $267-274$

Robohm, R. A., Brown, C., Murchelano, R. A. (1979). Comparison of antibodies in marine fish from clean and polluted waters of the New York bight: relative levels against 36 bacteria. Appl. environ. Microbiol. 38: 248-257

Rosenkvist-Jensen, L. (1983). Practical experience with vaccination of rainbow trout against vibriosis. Rapp. P.-v. Cons. int. Explor Mer 182: 121-125

Sørensen, U. B. S., Larsen, J. L. (1986). Serotyping of Vibrio anguillarum. Appl environ. Microbiol. 51 593-597

Taylor, S. M., Kilpatrick, D., Kenny, J. (1978). The influence of age and husbandry of pigs on evaluation of the enzyme linked immuno-sorbent assay (ELISA) for $T$. spiralis infection. Zentralbl. Veterinärmed. Reihe B 25: 282-289

Thorburn, M. A. (1986). Epidemiologic and economic aspects of vibriosis and its control in pen-reared rainbow trout (Salmo gairdneri) in Sweden. Ph. D. thesis, University of California, Davis

Thuvander, A., Hongslo, T., Jansson, E., Sundquist, B. (1987). Duration of protective immunity and antibody titres measured by ELISA after vaccination of rainbow trout, Salmo gairdneri Richardson, against vibriosis. J. Fish Dis. 10: $479-486$

van Loon, A. M., van der Logt, J. T M., van der Veen, J, (1981). Enzyme-linked immunosorbent assay for measurement of antibody against cytomegalovirus and rubella virus in a single serum dilution. J. clin. Pathol. 34: 665-669

Woodruff, A. W., de Savigny, D., Jacobs, D. E. (1978). Study of toxocaral infection in dog breeders. $\mathrm{Br}$ Med. J. 2: $1747-1748$

York, J. J., Fahey, K. J., Bagust, T J. (1983). Development and evaluation of an ELISA for the detection of antibody to ILT virus in chickens. Avian Dis. 27: 409-421 